\title{
Understanding the blast damage mechanisms in slopes using observations and numerical modelling
}

\author{
S.J. Etchells AEL Mining Services, South Africa \\ E.J. Sellers JK Tech Pty Ltd, Australia
}

J. Furtney Itasca Consulting Group Inc., USA

\begin{abstract}
Observations made in the field, together with numerical modelling using the Hybrid Stress Blast Model (HSBM) are presented to further understand the mechanisms contributing to blast damage in pit slopes. The aim being to examine the contributing variables such as the variability of the rock mass, blast design, charging technique and current wall control techniques in the industry. The HSBM blast modelling research tool, with some improvements to the near field logic, successfully demonstrates different techniques of wall control that are being used in the industry. It is shown how the orientation of the discontinuities relative to the pit walls can negatively affect the performance of both a presplit and a post -split if not taken into consideration in the blast design. Damage reduction in a presplit requires the correct spacing, decoupling ratio and split factor. Controlling the fractures at the end of a presplit becomes important if there is a need to reduce the number of holes per delay to control vibrations and air blast, because there is an accumulation of damage into the highwall at the end of each section.
\end{abstract}

The use of post-splitting is more favourable in terms of reducing production time. Dynamic post-splits at a hard rock quarry are studied and show fair results for jointing at an acute angle to the face. Poor ground conditions result when the jointing is at an obtuse angle relative to the face. This technique should only be used if the risk on the operation is appropriately managed, and the mine is sufficiently shallow.

An effective wall control technique relies on an effective trim blast. Observations highlight damage up to ten metres or more into the slope with poor blasting, if an ineffective wall control technique were to be applied. The numerical modelling confirms that the linear charge factor is the main contributing factor to damage, although it is closely related to the powder factor and cannot be considered in isolation. Limitation of confinement is the major link to limiting damage. By understanding blast damage mechanisms, pit slope stability risks can be better quantified and modelled. This will allow optimisation of a wall control technique to a specific rock mass, and to link the expected damage on a bench scale to the overall pit slope.

\section{$1 \quad$ Introduction}

Blast damage mechanisms are not well quantified or modelled phenomena. Recent observations have shown that there is a greater need to understand the accumulative effect of blast damage on overall slope stability. The importance of linking the blast design to obtain optimal production and the remaining integrity of the highwalls that the rock engineers need to manage thereafter is paramount to the success of the operation (Sellers et al., 2012b). Pit slope designs are optimised for maximum economic return with a quantified geotechnical risk. This often involves increasing the slope angle and the consequential additional risk from the reduced stability of the pit slope (Steffan et al., 2008). This paper will use observations made in the field, together with numerical modelling as a tool, in an attempt to understand the mechanisms contributing to blast damage, and to examine the contributing variables: variability of the rock mass, blast design, charging technique and current wall control techniques in the industry.

The effect of a few aspects of the blasting parameters in limit blasts have been modelled using the Hybrid Stress Blast Model (HSBM); a numerical tool that is able to model the blast from first principles using a continuum method for the near field crushing zone, coupled to a three-dimensional lattice fracturing 
discrete element code to model the far field, or blast movement. Improvements in the HSBM model using the Simple Model for Blasting (SMB) (Furtney et al., 2012a) allow us to understand better the partitioning of explosive energy into near field crushing or shock energy, gas venting, burden movement and other forms of energy controlling the breakout mechanisms (Furtney et al., 2012b; Sellers et al., 2013).

The damage resulting from the blast will be controlled by the rock mass, and the wall control technique used. The modelling process involves a simplification of the rock mass, and for the purpose of this analysis, categories of rock masses examined are hard and highly jointed rock. Wall control techniques investigated in this study include presplitting, and dynamic post-splitting. The resulting damage distributions are studied to understand the contributing mechanisms in the different rock masses. A study is done to confirm the controlling factor of linear charge to damage from trim blasting. This paper examines the damage mechanisms on a single bench scale. It has been identified as a next step that the damage predicted by the model on a bench scale by HSBM can be studied and calibrated in order to understand the mechanisms operating on a stack scale or overall slope scale by using the Large Open Pit (LOP) Slope Model. Understanding the mechanisms of blast damage will allow us to be able to develop improved ways of quantifying, and therefore, managing the risk from blast damage for optimised slope designs.

\section{$2 \quad$ Hybrid stress blasting model}

The HSBM is a high level blast modelling research tool which provides results that can still be used implicitly for practical blast design. The code is being developed through an international collaborative research project funded by a consortium of companies which is comprised of explosive, equipment suppliers and major mining houses. Details of the model can be found in Furtney et al. (2009). A non-ideal detonation code, Vixen2009, is used to define the detonation inputs (Braithwaite et al., 2009). In the standard model, a programmed burn implementation of detonation in the finite difference code FLAC (Itasca Consulting Group, 2011) applies load to the near-field rock, modelled with a Mohr-Coulomb material. The radial fracturing occurring away from the borehole is primarily tensile-mode failure and is represented with a lattice-model simplification as shown in a schematic in Figure 1(a).

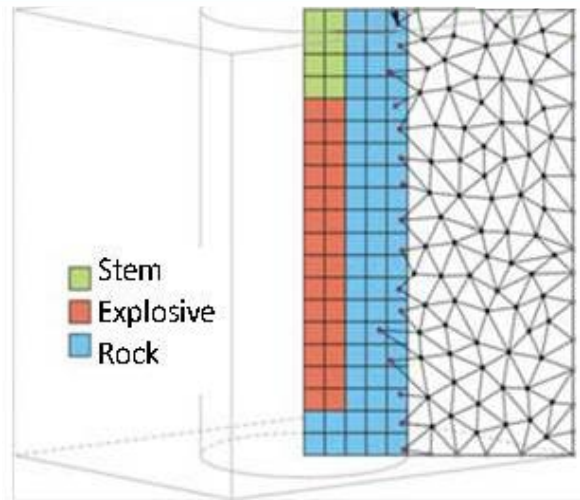

(a)

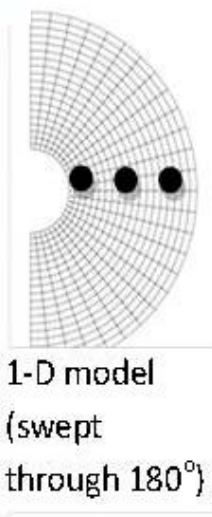

(b)

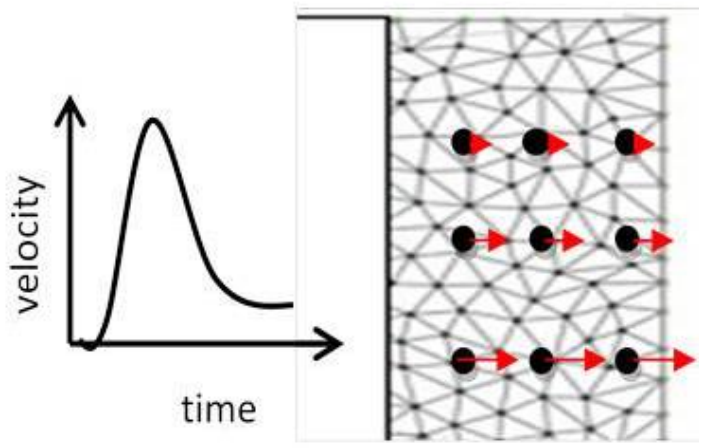

(c)

(d)

Figure 1 Schematics of (a) HSBM programmed burn and lattice model; (b) near-field simple model with data capture grid points; (c) dynamic loading curves; and (d) loading grid applied directly to lattice at Velocity of Detonation (VoD)

The three-dimensional lattice model representing the far-field rock mass is made up of point masses which are joined together by springs (Figure 2). The behaviour of the springs predominantly uses the tensile strength of the rock material. The lattice fracturing model allows joint planes to be inserted in the lattice, independent of position or direction (Cundall, 2011). Any springs intersected by a joint plane assume the properties of the joint, including orientation and direction. These are seen as 'joint springs' (Figure 2 (a)). 


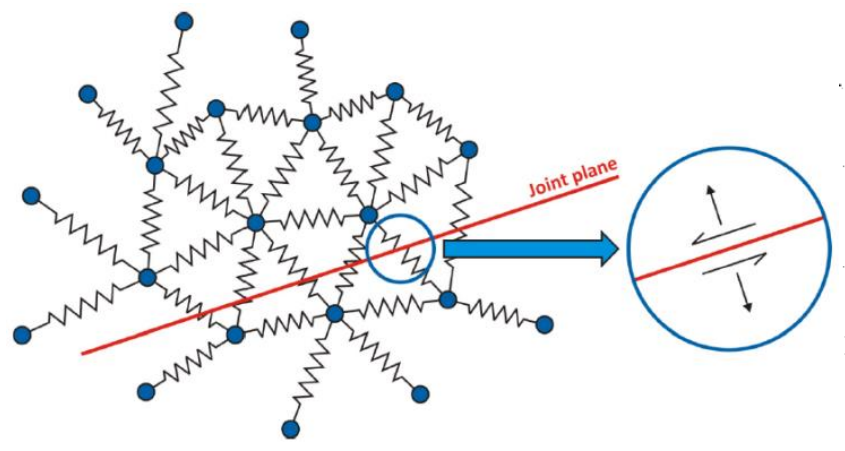

(a)

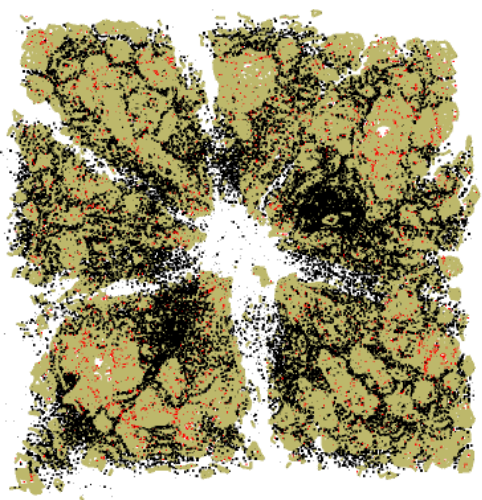

(b)

Figure 2 (a) Schematic of a lattice array made up of point masses (circles) and springs, and intersected by a joint plane; (b) discrete fractures (black) propagating through a rock mass and the respective damage (Itasca Consulting Group, 2012; Cundall, 2011)

The lattice model allows cracks to propagate without affecting the response of the elements or mesh regeneration, as in the case of a traditional continuum model (Itasca Consulting Group, 2012). Damage and fractures are modelled in the lattice framework by micro-cracks representing 'broken springs'. Fractures are micro-cracks which form the boundary of individual fragments. Fragments are collections of lattice nodes which are connected via intact springs. Damage is defined as micro-cracking which occurs within a fragment without causing complete separation. This is illustrated in Figure 2(b), by the lighter coloured rock mass showing the discrete fractures and damage.

Detonation of an explosive in a drillhole results in a gas pressurisation of the cavity, and a resulting shockwave travelling through the rock mass. This energy travels through the rock mass as a combination of shock and heave energy, and results in large strains and high stresses. The response of the rock is determined by both the explosive and the rock properties as described below (Brady and Brown, 2006):

- The strength of the explosive measured in Relative Effective Energy (REE).

- The ability of the rock material to transmit energy by Young's modulus and density.

- The ease of the material to generate new fractures by the uniaxial compressive strength and tensile strength.

- The density also affecting the energy required for movement of the broken rock material.

Recent work in applying Cavity Expansion Analysis (CEA) to blasting has shown that the rock response in the near-field is plastic in nature, as opposed to the traditional elastic models (Szendrei, 2013). Details of the difference from traditional elastic models and discussions can be found in Hustrulid (1999) and Sellers et al. (2013). CEA models show that the shock energy is the highest portion of the explosive energy, and most of the shock energy is used in the plastic deformation of the rock material in the near-field (Cunningham et al., 2007). The shock phase is also responsible for the stress wave: the stress wave creates softening of the rock mass by creating and extending micro-cracks. Mechanisms such as extension of long cracks, acceleration of the rock mass and secondary fragmentation by shear and impact are minor energy sinks, and depend on the behaviour of gas pressure release, i.e. good stemming, adequate burden, existence of open joints or cavities (Cunningham et al., 2007).

The HSBM model is able to give outputs for the detonation of bulk explosives at high pressures, the near field explosive/rock interaction, the subsequent damage, fragmentation and heave of broken material. Typical inputs required are the geometry of the blast bench, the explosive properties and detonation energies, drillhole layout, charging and timing details as well as an understanding of the rock mass characteristics. Considerable validation work has focussed on breakage, fragmentation and damage outcomes in controlled laboratory experiments and using large concrete cubes (Sellers et al., 2009; 
Onederra et al., 2012) and field scale blasts in kimberlite (Sellers et al., 2012a). A group of related issues and limitations has arisen as a result of Blo-Up's current near-field rock modelling method (Itasca Consulting Group, 2012). An experimental near-field model (Blo-Up version 2.6.1) was partially developed in December 2011. Improvements in the HSBM model using the Simple Model for Blasting (SMB) (Furtney et al., 2012a,b) allow us to understand better the partitioning of explosive energy into near-field crushing or shock energy, gas venting, burden movement and other forms of energy controlling the breakout mechanisms (Sellers et al., 2013). The simplified near-field model works by pre-solving for the early time crushing behaviour with a high resolution continuum model. Using the outputs from the detonation code a simple 1D axisymmetric model of the reaction product gas, the borehole and the near-field rock is constructed. The continuum geomechanics code FLAC (Itasca Consulting Group, 2011) is used in dynamic mode with a Mohr-Coulomb constitutive model to describe the near-field rock. The rock is represented as a cylindrical annulus Figure 1(b) with an inner diameter representing the borehole and an outer radius of $2 \mathrm{~m}$. The borehole is pressurised at a rate given by the velocity of detonation. The borehole gas pressure is applied to the inside surface of the annulus. The pressure is adjusted using the Equation of State (EoS) as the borehole expands, assuming the gas products expand isentropically (i.e. with a change in entropy). The near-field displacement caused by the explosive Figure 1(c) is recorded at a series of grid points and applied directly to the lattice as a velocity Figure $1(d)$, during local detonation. This model is similar to programmed burn, but now the near-field rock mechanical response is incorporated into the 'programmed burn'. The model switches from applying the velocity pulse to the gas cavity loading model, locally, at the time the equilibrium pressure is reached (around $0.5 \mathrm{~ms}$ after detonation). The gas cavity loading model has been improved to include the explosive isentrope, a more accurate volume calculation, axial flow, stemming flow and fracture flow. The practical advantages of this approach are:

- A better model of the equilibrium pressure, which results in more accurate movement.

- More realistic behaviour for different explosive types.

- Independence of response from hole length and a better transition to the expanding gas-cavity model.

- Overcoming spurious fracturing when boreholes are close together.

- Reduced resolution requirements leading to greater speed.

Validation work related to the ability of the HSBM model to represent limit blasting practices (Sellers et al., 2012a) showed that there is no need for the compression annulus during presplit blasting and that this zone obscured the formation of tensile cracks from the boreholes. A test version of the code was modified to remove the compression zone for presplits and apply the explosive loading directly to the lattice. Results in this paper confirm the benefit of this approach.

\section{$3 \quad$ Presplit blasting}

Presplit blasting is a well-known technique to produce a well-defined final wall on each bench (Wyllie and Mah, 2004; Hagan and Bulow, 2000; Cunningham, 2000; McKenzie, 2012; de Graaf and Etchells, 2013). Holes are drilled at a typical spacing of 8 to 13 diameters and lightly charged with decoupled explosives. When detonated simultaneously, the rock splits as if along a line of perforation as shown in Figure 3 . In practice, however, the protection provided to the slope is highly dependent on the care taken in the drilling, and also the design and implementation of the blast adjacent to the split. Figure 4 shows a situation where the blast has damaged the upper portions of the highwall face and regions weakened by discontinuities, which has resulted in localised slips. 


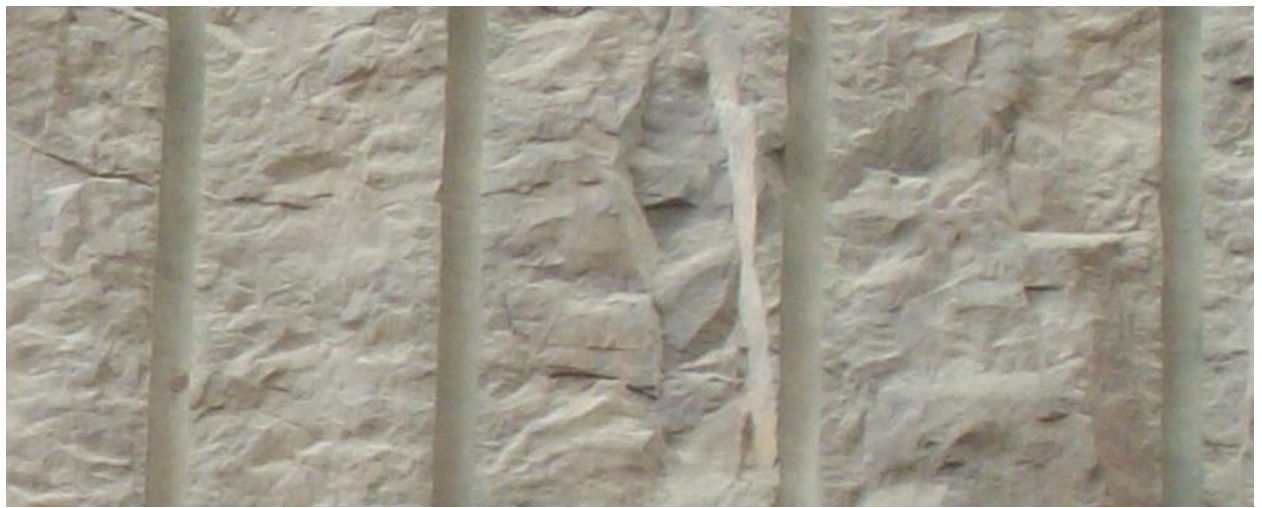

Figure 3 Example of presplitting in basalt (Oageng et al., 2008). Note where the holes are drilled closer on the left, the split is straighter. No fractures are evident in the barrel
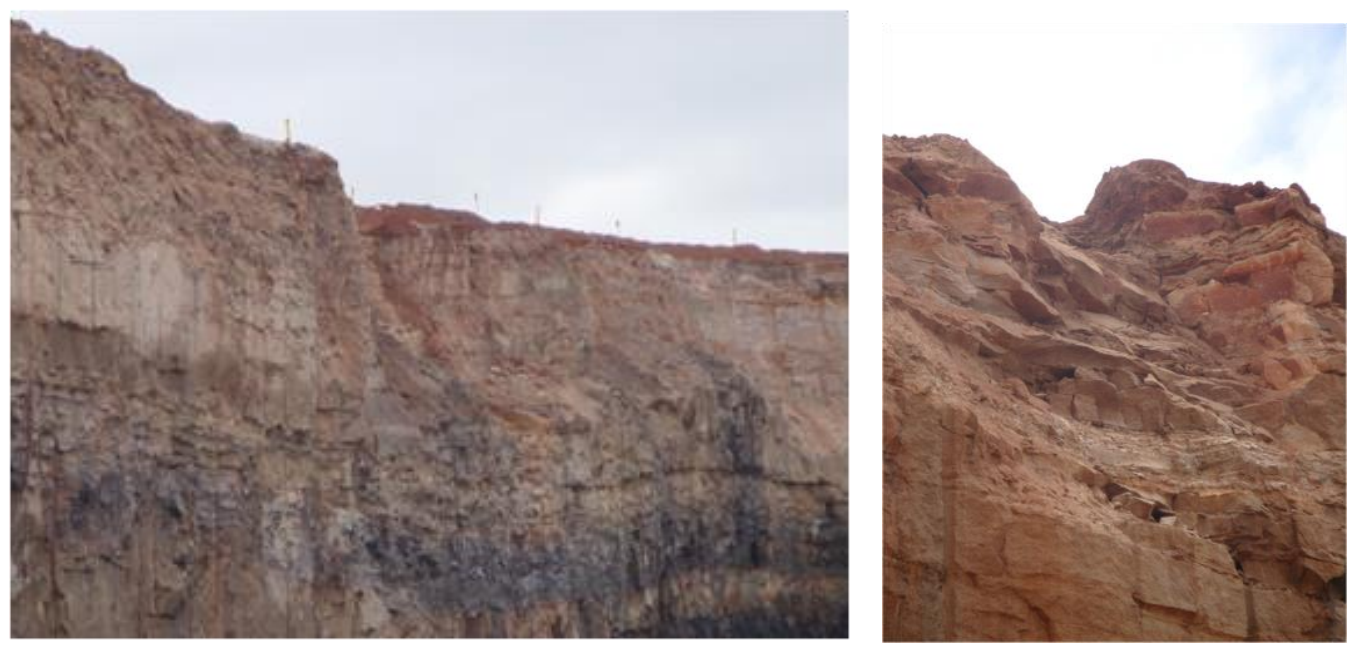

Figure 4 Presplitting in a South African coal mine. Note how the upper portions of the slope are damaged due to back damage from the main blast and slip on unfavourably oriented discontinuities

The benefits of performing presplits with small diameter charges in holes about 90 to $150 \mathrm{~mm}$ in diameter are well established. When the charge is decoupled and small enough that the detonation occurs with an annulus of air in the borehole, the pressure on the borehole is reduced to below the unconfined strength of the rock material, permitting the extension of tensile fractures between simultaneously detonated holes. The development of the tensile fracture does require a relatively massive rock mass and the presence of softer or highly jointed rock can obscure the presplit as shown in Figure 5(a). The sandstone layers have split well, but the jointed, friable mudstones show little effect of the split. Recently, production pressures are driving a move to large diameter holes with short decks of fully coupled explosive. The premise is that the theoretical volumetric decoupling ratio is the same and the loading is simplified and faster. However, cavity expansion theory (Sellers et al., 2013) indicates clearly that there is a considerable difference in mechanism between the coupled and decoupled conditions. When the charge is fully coupled, the pressure exceeds the unconfined strength of the rock causing local crushing. At the same time the holes are often spaced further apart. This creates a double damage action as shown in Figure 5(b). The fully coupled charge causes damage and fractures back into the highwall, and the excessive spacing leads to semi-circular faces as the tensile split does not form. 


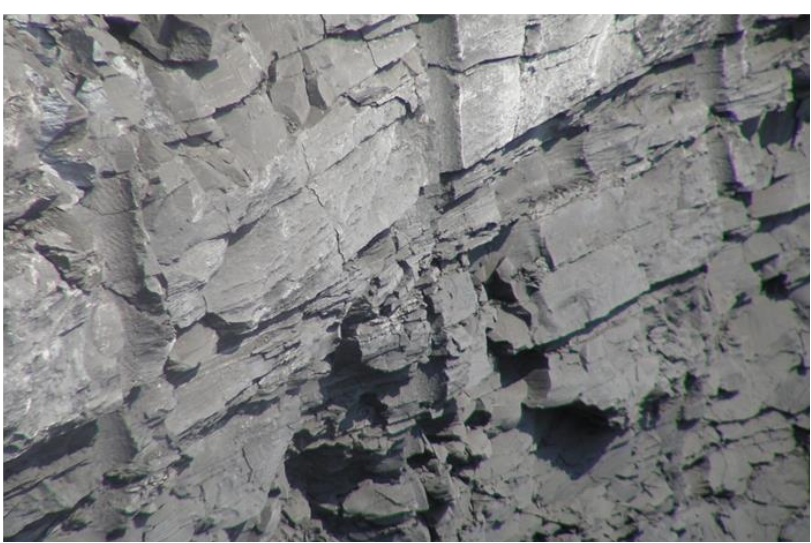

(a)

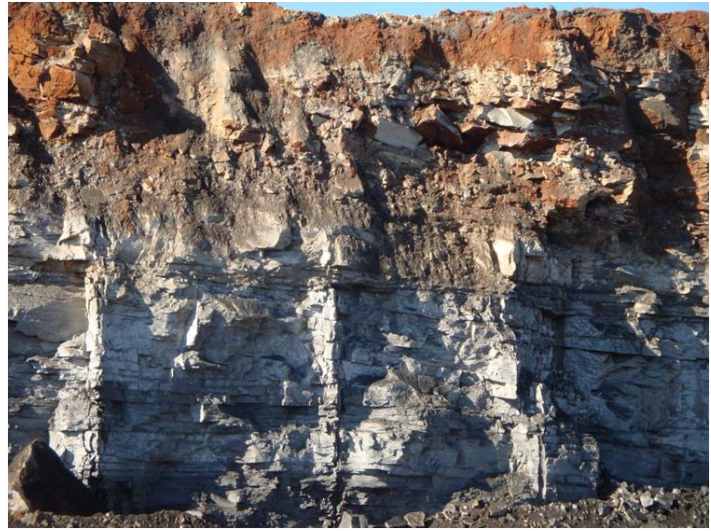

(b)

Figure 5 (a) A presplit in a coal mine showing how the split has worked well in the upper layer of massive sandstone, and not the lower mudstones and coal; and (b) attempt at presplitting using coupled, decked charges with excessive spacing causing semi-circular faces as the tensile split does not form

Numerical modelling work was done for a large open pit diamond mine to evaluate how the spacing and diameter would influence the presplit. In addition there was a requirement to limit vibrations and so there was a need to determine if firing a set of only five holes at a time would cause additional damage. Also, as neighbours encroach on the mines there is a stronger need to control airblast and vibrations. Presplit blasting using un-stemmed explosives and detonating cord on surface over long sets of holes is a major culprit, and so there is a strong desire to limit the number of holes firing simultaneously.

A HSBM model was set up to reproduce the presplit blast design. Illustrated in Figure 6 are the results when the hole diameter (D) is $100 \mathrm{~mm}$ and the charge diameter $(\mathrm{d})$ is $45 \mathrm{~mm}$, leading to a decoupling ratio $\left(\mathrm{D}^{2} / \mathrm{d}^{2}\right)$ of 5 . Note that this is a fairly low ratio for kimberlite rock and that $32 \mathrm{~mm}$ or $38 \mathrm{~mm}$ charges would be more common.

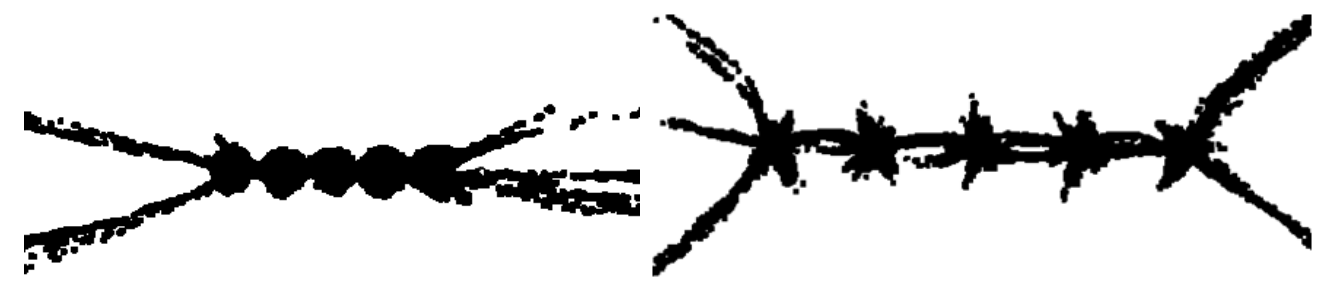

(a)

(b)

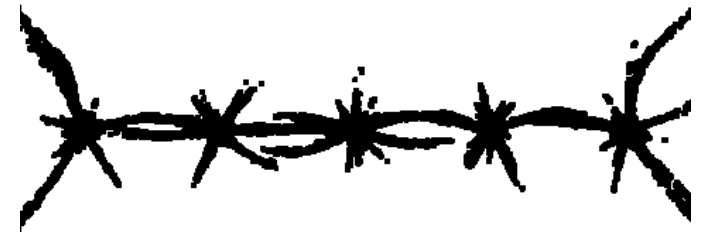

(c)

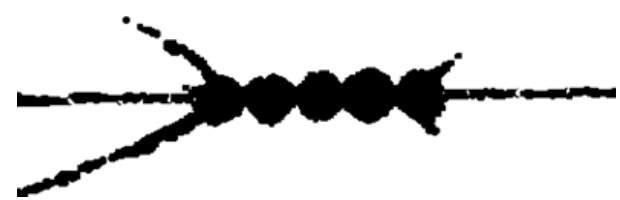

(d)

Figure 6 Modelled presplits for a decoupling ratio of 5; (a) $0.8 \mathrm{~m}$ spacing; (b) $1.5 \mathrm{~m}$ spacing; (c) $2 \mathrm{~m}$ spacing; and (d) $0.8 \mathrm{~m}$ spacing with an empty hole at half a spacing to the right

The results of initial studies shown in Figure $6(\mathrm{a})$ indicate that the spacing of $0.8 \mathrm{~m}$ is too close and results in localised damage. There is a considerable extent of fracturing emanating from the sides of the five hole split section implying that dividing the split into shorter sections can result in additional damage to the remaining highwall. Expanding the spacing to $1.5 \mathrm{~m}$ (Figure 6(b)) leads to less damage at the central holes and straighter cracks in between the holes. The damage at the ends extends at a much more oblique angle 
into the face. If the spacing is expanded further to $2 \mathrm{~m}$ (Figure $6(\mathrm{c})$ ) there tends to be excessive bowing of the fractures between the holes. It is of interest to observe that the model predicts that fractures extend from the hole outwards and not from between the holes as applied in many simplified presplit designs that only consider static and constant stress distributions. It is the extension from the holes outwards that leads to the tendency for the face to become concave for larger spacings. In this model, the optimal spacing of less than $1.5 \mathrm{~m}$ is consistent with the design rules of thumb of 8 to 13 hole diameters (McKenzie, 2012).

Since the damage extends substantially at the edge holes of the split section, limiting the number of holes in the presplit sections would assist with vibration control and yet hamper the prevention of highwall unravelling. A suggestion to add an uncharged hole of half a diameter from the section end that would assist in driving the fractures along the split was tested with the model as shown on the right hand side in Figure 6(d). This suggestion seems to work, although further testing indicates that holes spaced up to one burden would also assist in this process, and would be a more practical solution. Thus, the uncharged holes in the split may be sufficient to limit the damage, though the explosive gas products may compromise the quality of the explosives in the next split section.

\section{$4 \quad$ Dynamic post-split blasting in hard rock}

Post-split blasting is generally undertaken in situations where the highwall stability is less critical, for example when the mine is expected to remain shallow. In conventional post-split blasting, the main production blast is taken and then a single line of holes is drilled and blasted, preferably using decoupled explosives, to clean the face and leave a smooth surface, hence the typical terminology 'smooth wall blasting' (Hagan and Bulow, 2000). At a hard rock quarry in Johannesburg, the post-split technique has been modified to fire the last row with the delay timing double that of the inter-row timing of the rest of the blast. This is facilitated by easily programmed electronic detonators and provides a dynamic version of the standard post-split or smooth wall blast. Modelling studies are then presented to understand why the post-split provides an improved face, and how the jointing is influencing the fracture patterns.

Two faces from production blasts at the hard rock mine are shown in Figure 7 to indicate how the damage is altered by the relationship between the face and in situ rock mass structure. Production blasting in a southerly direction produces a saw tooth face profile as shown in Figure 7(a). Mining at right angles in a westerly direction produces a more blocky profile. The next question to answer is whether the postsplitting can be equally effective in both directions?

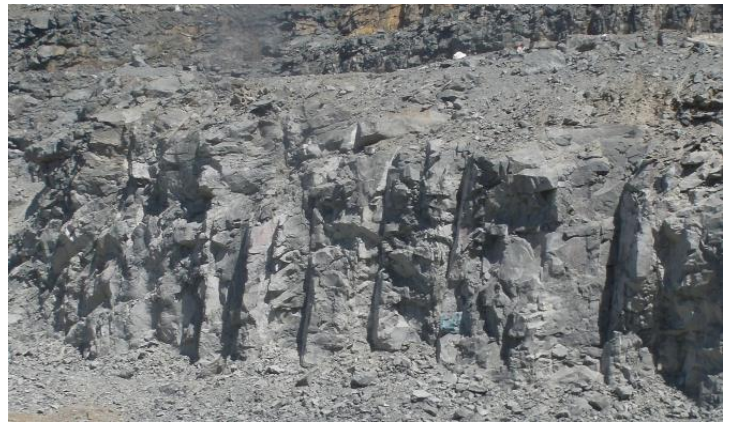

(a)

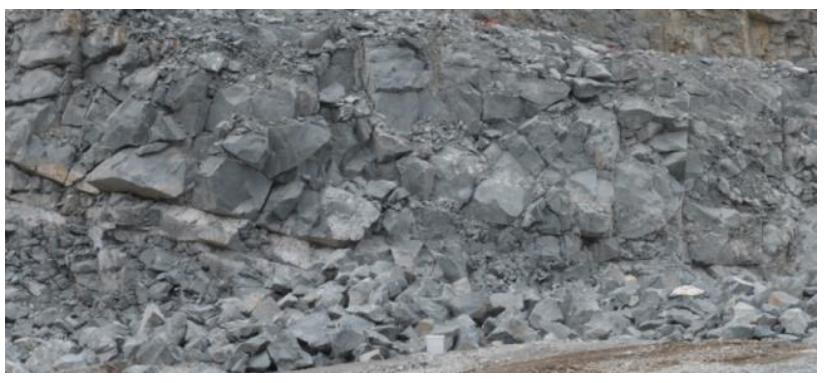

(b)

Figure 7 Face profiles from production blasting in (a) southerly direction; and (b) westerly direction

Figure 8(a) shows a wide view of the pit to emphasise the effectiveness of the dynamic post-split on northern pit slopes (left hand view) and the contrasting poor performance on the western slopes (right hand view). Thus, when the jointing is at an acute angle in the face (Figure $8(d)$ ) the rock splits neatly between the blast holes shown in Figure $8(\mathrm{~b})$, whereas the split is less successful when the jointing is at an obtuse angle to the face. However, a closer look at the rock in Figure 8(c) reveals significant damage around the hole, which is to be expected with the fully coupled emulsion charge. Sliding of the rock on the 
damaged upper portions of the face permit a view into the rock mass and shows how the blast fractures extend radially backwards from the blast hole barrel.

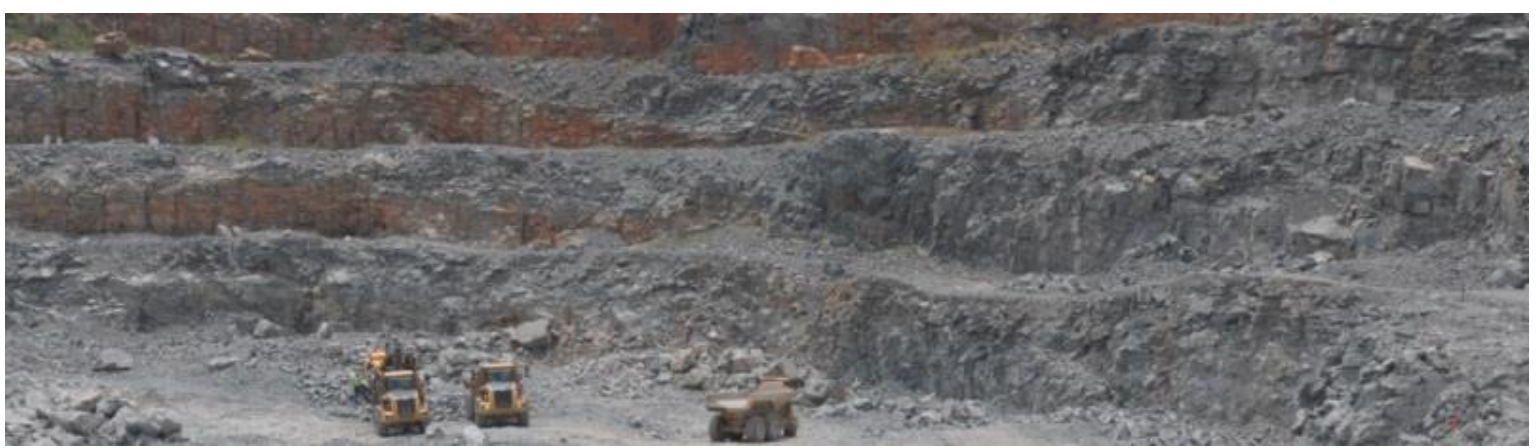

(a)

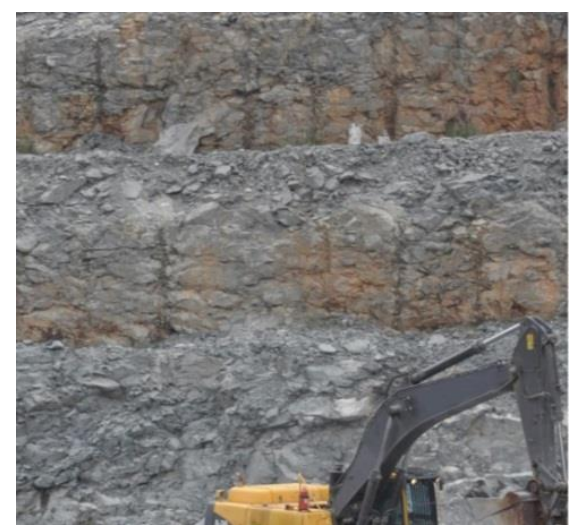

(b)

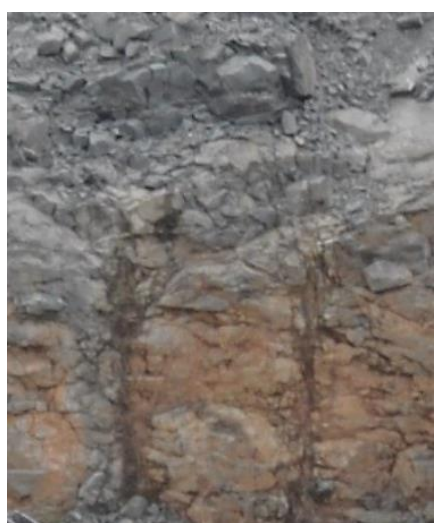

(c)

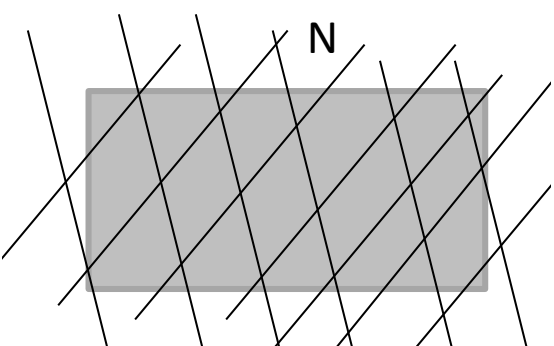

(d)

Figure 8 (a) Dynamic post-splitting on the north (left view) and west slopes (right view); (b) detail of the splits on the north slopes; (c) close up of the damage; and (d) sketch of jointing relative to pit plan orientation

An HSBM model of the mine as shown in Figure 9(a) was set up using a representative two rows of holes in order to speed up the parametric studies. The characteristic back damage profile is shown after running the model for 650 ms (Figure 9(b)).

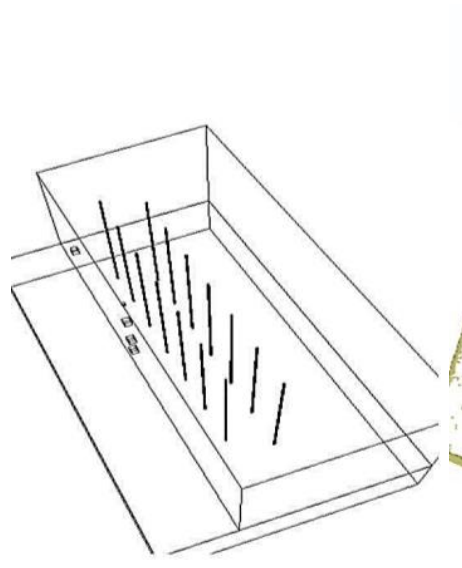

(a)

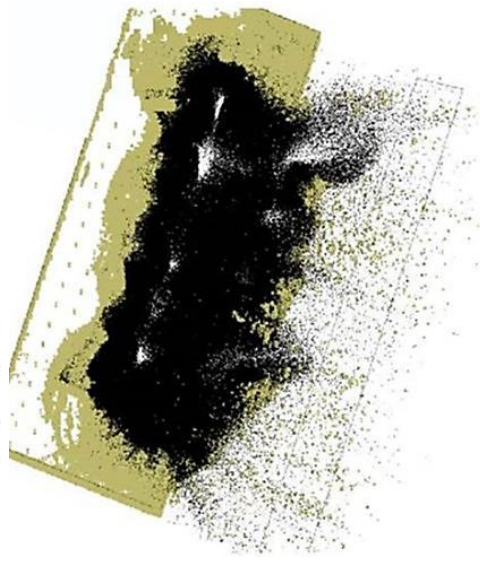

(b)

Figure 9 (a) HSBM model of a hard rock blast; and (b) results after $650 \mathrm{~ms}$

For the model in Figure 9, we added two sub-vertical joint sets with dip directions at $\pm 50^{\circ}$ and dipping at $80^{\circ}$ to the face with a third set dipping $10^{\circ}$ to the face (Figure 10). These joints have a limited tensile 
strength of $25 \%$ of the rock strength to represent the cumulative effect of lack of persistence and small directional variations. All joint sets were spaced at $1 \mathrm{~m}$ on average with a Gaussian distribution having a standard deviation of $0.2 \mathrm{~m}$. The inclusion of jointing alters the damage pattern considerably. Figure 10(a) shows that the joints fracture almost two burdens behind the last row. The damage pattern is controlled by the sub-vertical joint directions. The detail of the remaining face shown in Figure 10(b) indicates the saw-tooth shape shown in the real situation in Figure $7(a)$, which provides some confidence in the model representation. When delaying the last row of holes by doubling the inter row delay, there does not seem to be much difference in the face shape, though the damage back into the high wall is more obvious, which is the opposite of the expectation. An interesting feature is the solid line of fracturing parallel to the face that is exhibited in the detail of Figure 10(d). This is barely visible in the run with standard timing, suggesting that the delayed back row has limited the back damage and also is cutting a cleaner face, as the rock will be loaded to that straight line fracture. The HSBM model does exhibit a total loss of cohesion of the rock behind the barrel that is not obvious in single line blasts in practice, where the tendency is to break off and show a line of barrels on the face as in Figure $8(b)$. This will require further research as part of the main HSBM development project.

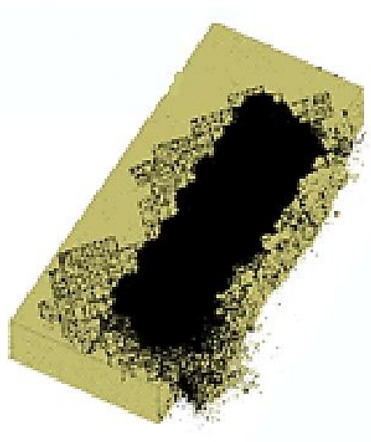

(a)

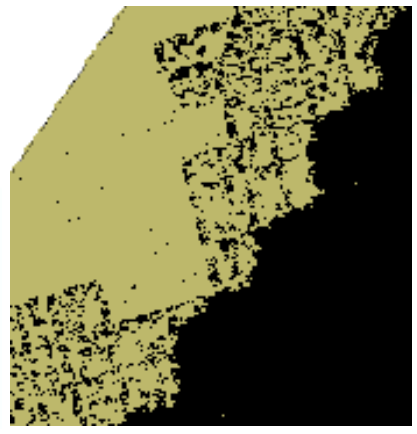

(b)

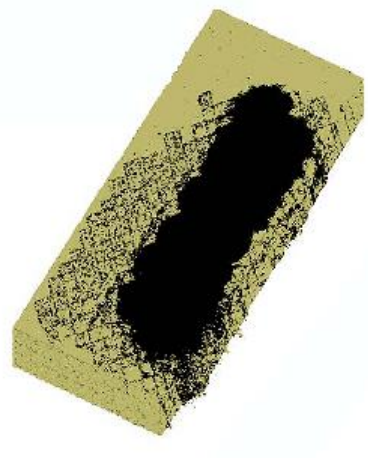

(c)

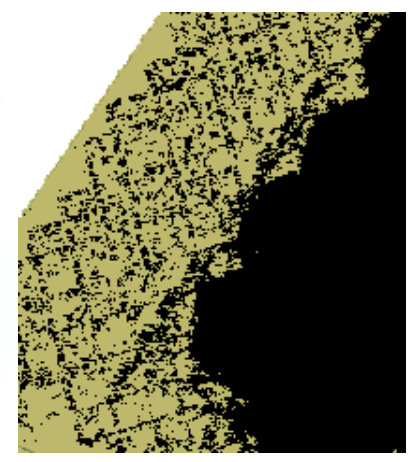

(d)

Figure 10 Influence of adding joints; (a) same burden timing with; (b) detail showing saw tooth face as per Figure $7(a)$; and (c) delayed timing on second row - more damage? Minimal change in face 'cleanness'; (d) detail showing straight line of fracture - is that the split working?

\section{$5 \quad$ Damage extent in the trim - powder factor or linear charge?}

McKenzie (2012) raised the question as to whether it is the powder factor or the linear charge that determines the extent of damage into the highwall from the trim blast and concluded that the linear charge appears to be the controlling factor. In this work, we wished to assist in evaluating which of the two is more pertinent by using the HSBM model. In this case we reconsider the results from Sellers et al. (2012a and 2012b), where blasting of $10 \mathrm{~m}$ high benches in kimberlite using $165 \mathrm{~mm}$ holes was studied. Figure 11 repeats the full muckpile shapes two seconds after blast initiation for a range of powder factors and shows how the throw increases with the increase in powder factor. It is evident that the back break increases significantly as the powder factor decreases, for a given hole diameter, as is highlighted in Figure 11. To decrease the powder factor it is necessary to increase the burden and so, as the blast becomes underpowered the confinement on the back rows increases and hence the cracks tend to extend further. In the case that the powder factor is kept constant, the hole diameter is increased to $250 \mathrm{~mm}$ and the burden needs to be increased. A comparison of Figure 11(a), with $165 \mathrm{~mm}$ holes, and Figure 11(d), with $250 \mathrm{~mm}$ holes, shows clearly that the larger diameter causes more damage. Hence the conclusions of McKenzie (2012) are valid and supported by the modelling. The use of large holes for improved production will lead to a significantly larger damage extent. Though, given the constraints of blasting it is necessary to consider both powder factor and linear charge density as they are interrelated. The only option to reduce damage is to decouple using a thinner charge along the hole axis. Decoupling of larger holes using short, coupled decks will not prevent the larger extent of damage, at least in the coupled regions. 


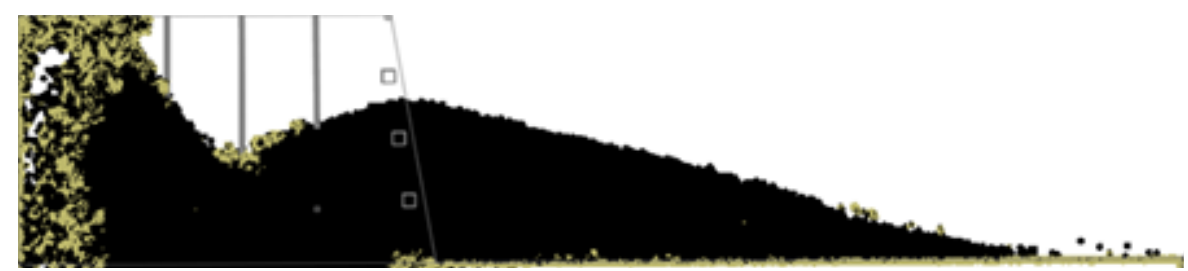

(a)

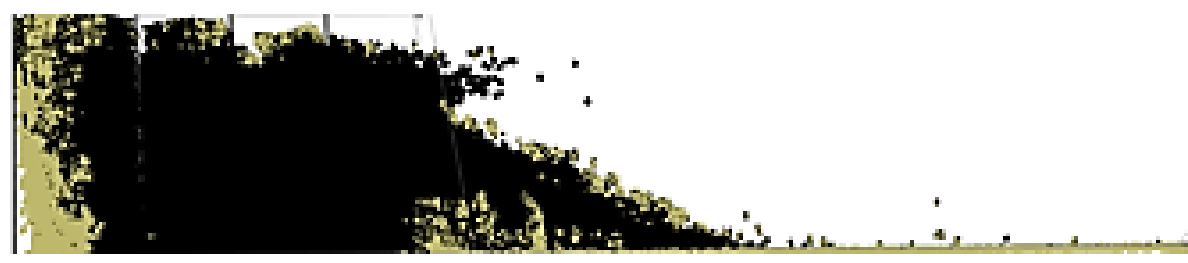

(b)

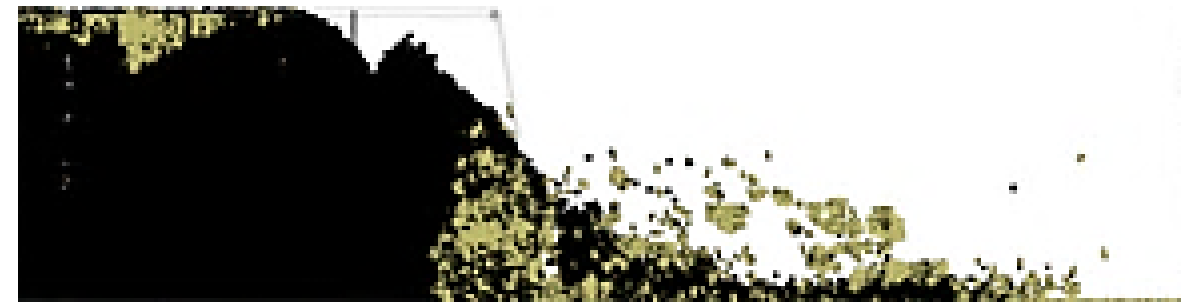

(c)

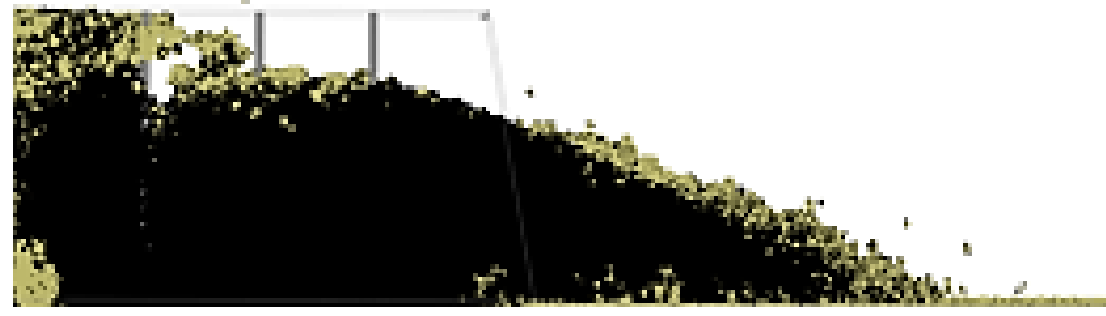

(d)

Figure 11 Muck pile shapes and details of back damage for powder factors of; (a) $1.2 \mathrm{~kg} / \mathrm{m}^{3}$; (b) $0.72 \mathrm{~kg} / \mathrm{m}^{3}$; (c) $0.44 \mathrm{~kg} / \mathrm{m}^{3}$ in $165 \mathrm{~mm}$ holes; and (d) $1.2 \mathrm{~kg} / \mathrm{m}^{3}$ for a $250 \mathrm{~mm}$ diameter hole

\section{$6 \quad$ Impact of blasting on slope design}

Poor wall control techniques have a long term impact on reducing the performance of the slope design. On the skin of the slope, rock falls are aggravated by poorly formed final walls, and this is worsened in the case of unfavourable joint orientations. A poorly controlled blast has the effect of creating new fractures, and causing significant movement of the rock mass (Figure 12(a) and (b)) which may open up pre-existing joints decreasing the in situ safety factor. Observations in the field have shown that back damage can extend a significant distance into the rock mass. This can obviously be much greater with the occurrence of unfavourably orientated joints, or large amounts of energy directed into the rock mass for example due to poor timing or poor burden relief. Figure 12(c) shows a kimberlite rock mass subjected to production blast damage (Figure 12(d)), and the opening up and extension of a horizontal crack running approximately ten metres back into the solid rock mass. Vertical cracks extend perpendicular to the face in Figure 12(d), visible on the surface approximately five metres from the damaged crest. Similar damage has been observed on poorly executed trim blasts resulting in damage to the final high wall despite the presence of a presplit, or a poorly designed post-split. Not all the damage is immediately visible, and in many cases only becomes apparent in the long term. 


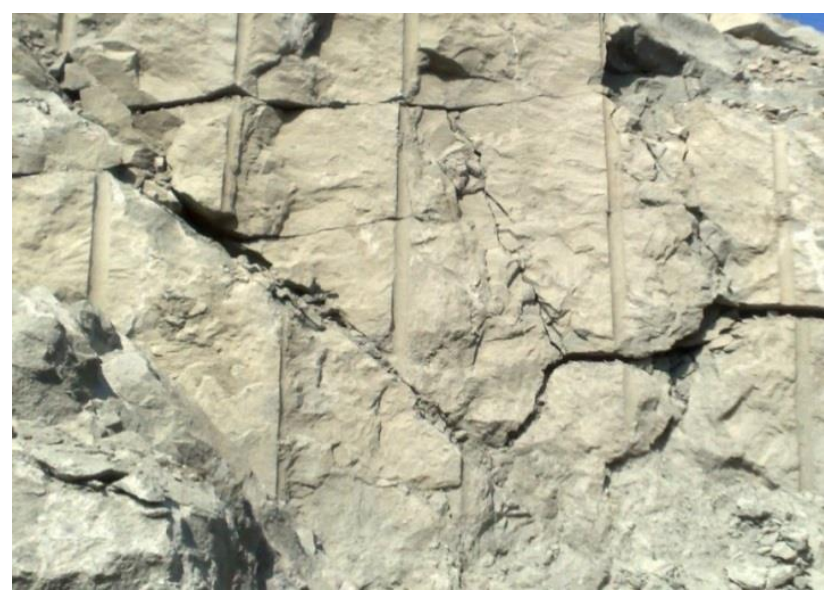

(a)

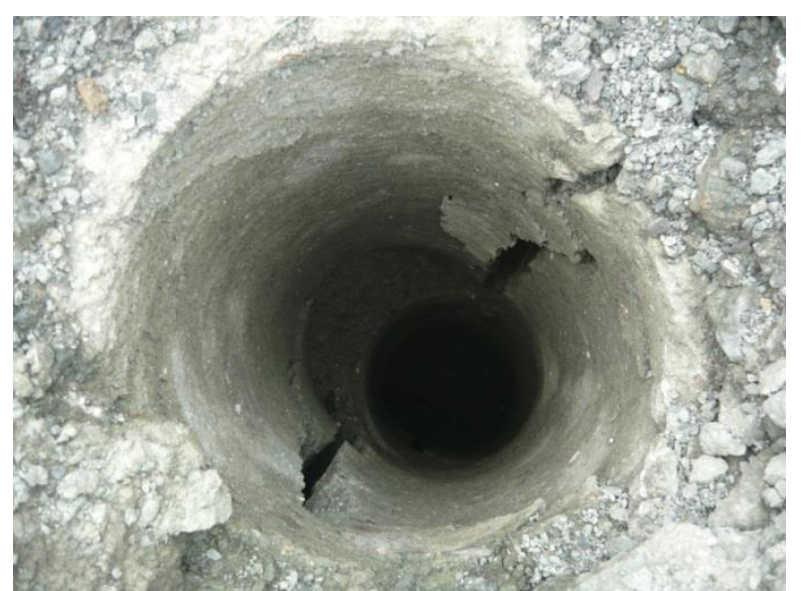

(b)

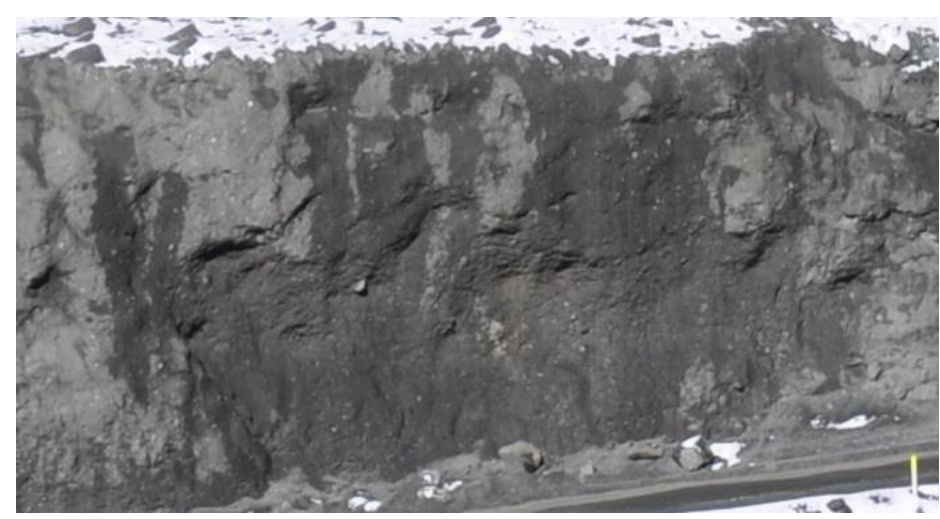

(c)

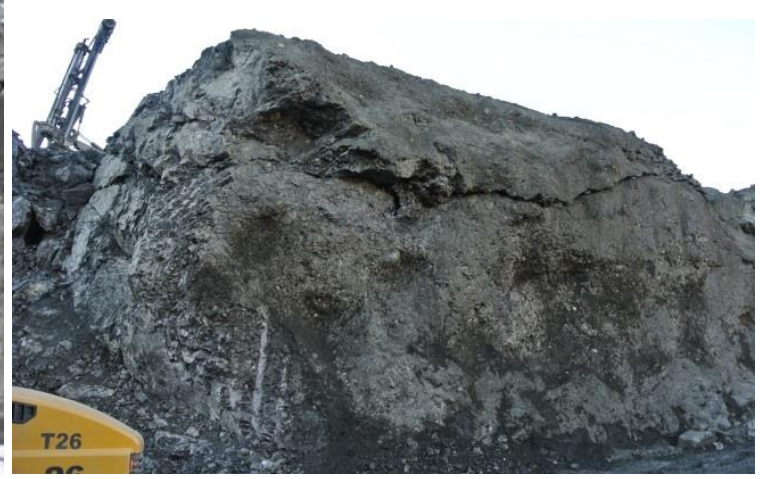

(d)

Figure 12 A kimberlite rock mass that; (a) shows more than $0.5 \mathrm{~m}$ movement along a pre-existing joint plane after a production blast; and (b) at least $10 \mathrm{~cm}$ column shift on a presplit; (c) The rock mass before; and (d) after showing opening up and extension of crack in a production blast damaged cross section extending backwards along the face

The damaged rock mass has a reduced Rock Mass Rating (RMR) and ultimately leads to the unravelling of the highwall, or localised failures in jointed rock masses. This is accommodated in the design of the slope by means of an adjustment factor ranging from $80 \%$ for poor blasting to $100 \%$ for no damage to give a Mining Rock Mass Rating (MRMR) (Laubscher, 1990). The end result if poor blasting is taken into account in the design can lower the slope angle by a few degrees (Haines and Terbrugge, 1991), increasing the amount of waste tonnes to be stripped by a few million tonnes, and costing billions of rands (Read and Stacey, 2009).

Poor perimeter blasting can result in excessive damage to the highwalls, not allowing the slope to be steepened. Badly damaged highwalls exposes the operation to significant risk by way of catchment berms which may be compromised in their retention of catching loose material, being filled to capacity much earlier in their design life by the increased volumes of rock falls and unravelling material. The catchment berms may also be compromised due to reduced width from excessive back break and damaged crests, or toes due to poorly designed limit blasts. Figure 14 shows an example of this in basalt where the rock is in theory very strong, but due to poorly formed catchment berms and unfavourable jointing, the ramp below is at significant risk from falls of ground. This risk can be managed by way of the introduction of extra distance on the catchment berms, resulting in flatter slope angles, reduced exposure of ore, and increased waste stripping (Figure 13). The extent of damage extending into the rock mass is an area of further research that is being investigated by using the HSBM model to model the damage to the rock mass, and the LOP Slope Model to understand the long term slope stability issues that may arise out of this. 


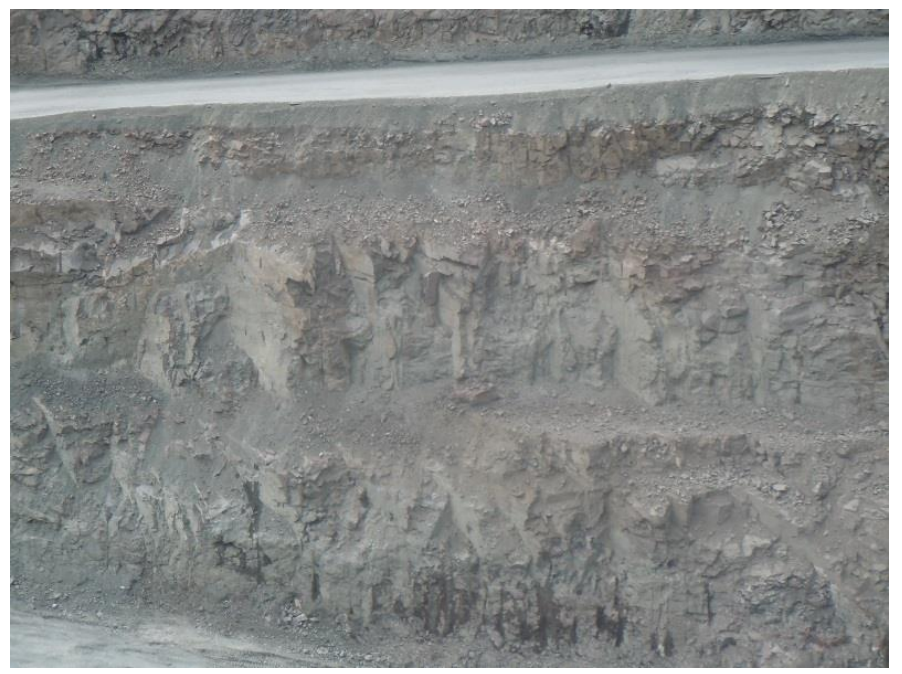

Figure 13 Poor performance of catchment berms placing the operation at significant risk

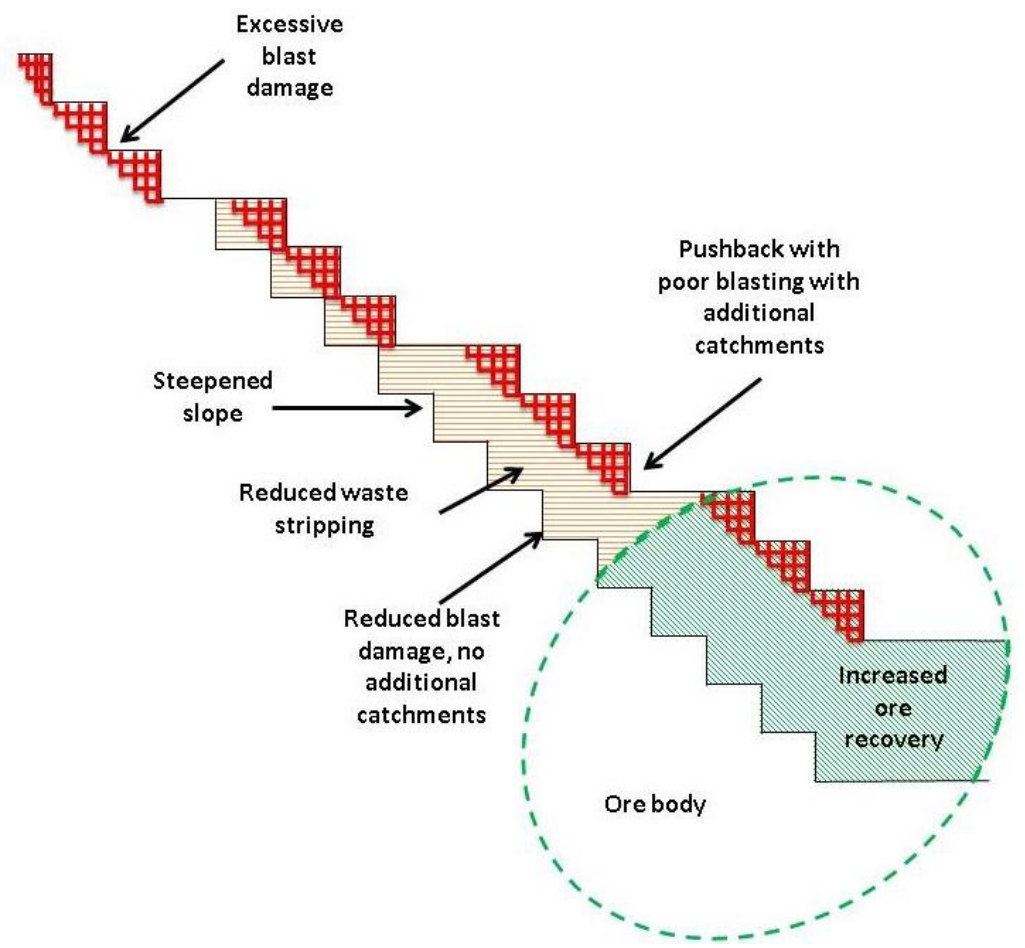

Figure 14 Pushback designs comparing a steepened slope with an existing slope with excessive blast damage

\section{Conclusions}

The stability of the slope highwalls is paramount in the return on investment being realised in an open pit mine, and for the risk to be quantified and managed. An optimised slope angle implies that the mining processes are optimised in conjunction with the slope design in order to implement a design that is effective. Blasting, by virtue of its nature, can cause significant damage to the rock mass unless controlled blasting is understood and implemented on an operation, specific to the rock mass characteristics, including the joint orientations and rock strengths. Poor final limit blasting techniques result in unsafe highwalls, and excessive risk being carried by the operation.

The HSBM blast modelling research tool is used to successfully demonstrate different techniques of wall control that are being used in the industry: presplit blasting and dynamic post-split blasting. Recent improvements have been made in the HSBM model to allow for improved modelling of wall control 
techniques, and will continue as part of the on-going research collaboration study. The extensive validation studies that are being conducted by the various sponsors of the project allow for improved confidence in the use of HSBM; and numerical modelling for comparative studies of blast design and understanding blast damage is a growing practice. Recent advances in the study of CEA have allowed us to better understand the impact of using decoupled charges and the benefit from reduced damage.

It has been shown that the effect of the orientation of the discontinuities relative to the pit walls can negatively affect the performance of both a presplit and a post-split if not taken into consideration in the blast design. The mechanisms of reducing damage in a presplit are shown by using different spacing's in order to minimise the impact of the localised damage from the blasting of the split itself, although this will depend on the decoupling ratio and the split factor used. A study at a large open pit diamond mine showed that by leaving a hole at the end of the split half a spacing distance away from the last charged hole, drives the end fractures along the split at an oblique angle away from the highwall. This still needs to be tested for a normal hole diameter spacing, although all indications are this will have the same effect, and be more practical to implement on a floor level due to a constant spacing of holes. Controlling the fractures at the end of a presplit becomes important if there is a need to reduce the number of holes per delay to control vibrations and air blast, because at the end of each section on each delay there is an accumulation of damage into the highwall.

The use of post-splitting is more favourable in terms of reducing production time, but is not as effective in wall control as a presplit in a hard rock situation. It is generally used where the stability of the highwalls is less critical, for example in shallow mines (i.e. quarries). A dynamic post-split is studied from a hard rock quarry, and fair results are shown for favourable jointing at an acute angle to the face. Poor ground conditions result when the jointing is at an obtuse angle relative to the face, and adequate measures should be taken to ensure the continued safety of the workers and equipment below these highwalls with the increased risk of rock falls. This technique should only be used if the risk on the operation is appropriately managed, and the mine is sufficiently shallow.

An effective wall control technique is only as effective as the trim blast that precedes it. Observable damage from a production blast can easily extend up to ten metres or more if adequate measures are not taken to control the amount and direction of energy in the rock mass. It was shown using numerical modelling that the work done by McKenzie, (2012), on the linear charge factor in trim blasting, is in fact supported in the HSBM model, and is the main contributing factor to damage in trim blasts, although it is closely related to the powder factor and cannot be considered in isolation.

By understanding blast damage mechanisms, the phenomena can be better quantified and modelled. This will allow us to optimise a wall control technique to a specific rock mass, and to model the expected damage on a bench scale. Ultimately, the study needs to extend to an overall pit slope to enable rock engineers to effectively manage the pit slope stability and the associated risks.

\section{References}

Brady, B.H. and Brown, E.T. (2006) Rock Mechanics For Underground Mining, 3rd edition, Springer, The Netherlands, 520 p.

Brithwaite, M., Sharpe, G. and Chitombo, G. (2009) Simulation of real detonations as an energy source term for the Hybrid Stress Blasting Model, in Proceedings 9th International Symposium on Rock Fragmentation by Blasting, J.A. Sanchidrián (ed), Fragblast 9, 13-17 September 2009, Granada, Spain, Taylor \& Francis, London, pp. 327-333.

Cundall, P. (2011) Lattice method for modeling brittle, jointed rock, in Proceedings 2nd International FLAC/DEM Symposium, D. Sainsbury, R. Hart, C. Detournay and M. Nelson (eds), Continuum and Distinct Element Modeling in Geomechanics, 14-16 February 2011, Melbourne, Australia, Itasca International Inc., Minneapolis, Keynote Lecture, Paper 01 02, pp. 11-19.

Cunningham, C. (2000) Use of blast timing to improve slope stability, in Proceedings Slope Stability in Surface Mining, W.A. Hustrulid, M.K. McCarter and D.J.A. Van Zyl (eds), Society for Mining, Metallurgy, and Exploration, Inc. (SME), Colorado, USA, pp. 131-134.

Cunningham, C., Sellers, E. and Szendrei, T. (2007) Cavity expansion energy applied to rock blasting, in Proceedings 4th EFEE World Conference on Explosives and Blasting, 9-11 September 2007, Vienna, Austria, European Federation of Explosives Engineers, United Kingdom, pp. 27-39.

de Graaf, W.W. and Etchells, S.J. (2013) Blast induced damage mechanism on final walls and the blasting methods to minimise damage, in Proceedings International Symposium on Slope Stability in Open Pit Mining and Civil Engineering (Slope Stability 
2013), P.M. Dight (ed), 25-27 September 2013, Brisbane, Australia, Australian Centre for Geomechanics, Perth, pp. 1315-1326.

Furtney, J., Cundall, P. and Chitombo, G. (2009) Developments in numerical modelling of blast induced rock fragmentation: Updates from the HSBM Project, in Proceedings 9th International Symposium on Rock Fragmentation by Blasting, J.A. Sanchidrián (ed), Fragblast 9, 13-17 September 2009, Granada, Spain, Taylor and Francis Group, London, pp. 335-342.

Furtney, J., Sellers, E.J. and Onederra, I. (2012a) Simple models for gas flow and burden movement during blasting, in Proceedings 38th Annual Conference on Explosives and Blasting Technique, ISEE 2012, 12-15 February 2012, Nashville, Tennessee, USA, International Society of Explosive Engineers Inc., Ohio, USA.

Furtney, J., Sellers, E.J. and Onederra, I. (2012b) Simple models for the complex process of rock blasting, in Proceedings 10th International Symposium on Rock Fragmentation by Blasting, P.K. Singh and A. Sinha (eds), Fragblast 10, November 2012, New Delhi, India, Taylor and Francis Group, London, pp. 275-282.

Hagan, T.N. and Bulow, B. (2000) Blast Designs to Protect Pit Walls, in Proceedings Slope Stability in Surface Mining, W.A. Hustrulid, M.K. McCarter and D.J.A. Van Zyl (eds), Society for Mining, Metallurgy and Exploration, Inc. (SME), Colorado, USA, pp. $125-130$.

Haines, A. and Terbrugge, P. (1991) Preliminary estimation of rock slope stability using rock mass classification systems, in Proceedings 7th International Conference on Rock Mechanics, W. Wittke (ed), ISRM Congress, September 1991, Aachen, Germany, Balkema, Rotterdam, Vol. 2, pp. 887-892.

Hustrulid, W. (1999) Blasting principles for open pit mining, Taylor and Francis Group, Florida USA, Vol. 2 Theoretical Foundations, $1013 \mathrm{p}$.

Itasca Consulting Group (2011) FLAC user's guide version 7.0, Itasca International Inc., Minneapolis.

Itasca Consulting Group (2012) Blo-Up user's guide release 2.7., Itasca International Inc., Minneapolis, $142 \mathrm{p}$.

Laubscher, D.H. (1990) A geomechanics classification system for the rating of rock mass in mine design, Journal of South African Institute for Mining and Metallurgy, SAIMM, Vol. 90, No. 10, pp. 257-273.

McKenzie, C. (2012) Limit blast design: Controlling vibration, gas pressure and fragmentation, in Proceedings 10th International Symposium on Rock Fragmentation by Blasting, P.K. Singh and A. Sinha (eds), Fragblast 10, November 2012, New Delhi, India, Taylor and Francis Group, London, pp. 85-94.

Oageng, K., Joseph, R. and Munyadzwe, I. (2008) Perimeter control at Orapa Diamond Mine, in Proceedings The International Conference on Surface Mining 2008, August 2008, Johannesburg, South Africa, The Southern African Institute of Mining and Metallurgy, Johannesburg, pp. 137-151.

Onederra, I., Furtney, J. and Sellers, E. (2012) Modelling the extent of damage from fully coupled explosive charges, in Proceedings 10th International Symposium on Rock Fragmentation by Blasting, P.K. Singh and A. Sinha (eds), Fragblast 10, November 2012, New Delhi, India, Taylor and Francis Group, London, pp. 267-274.

Read, J. and Stacey, P. (2009) Guidelines for open pit slope design, CSIRO Publishing, Australia, $496 \mathrm{p}$.

Sellers, E.J., Dippenaar, L. and Ruest, M. (2009) Large scale concrete cube blasts for the HSBM Model, in Proceedings 9th International Symposium on Rock Fragmentation by Blasting, J.A. Sanchidrián (ed), Fragblast 9, 13-17 September 2009, Granada, Spain, Taylor and Francis Group, London, pp. 389-398.

Sellers, E., Furtney, J. and Onederra, I. (2012a) Field-scale modelling of blasting in kimberlite using the Hybrid Stress Blasting Model, in Proceedings 38th Annual Conference on Explosives and Blasting Technique, ISEE 2012, 12-15 February 2012, Nashville, Tennessee USA, International Society of Explosive Engineers Inc., Ohio, USA.

Sellers, E., Furtney, J., Onederra, I. and Chitombo, G. (2012b) Improved understanding of explosive - rock interactions using the Hybrid Stress Blasting Model, Journal of South African Institute for Mining and Metallurgy, SAIMM, Vol. 112, August 2012, pp. 721-728.

Sellers, E.J., Etchells, S.J., Furtney, J., Kotze, M. and Szendrei, T. (2013) What broke the burden? Improving our understanding of burden breakout, in Proceedings 39th Annual Conference on Explosives and Blasting Technique, ISEE 2013, 10-13 February 2013, Fort Worth, Texas USA, International Society of Explosive Engineers Inc., Ohio, USA.

Steffan, O.K., Contreras, L.F., Terbrugge, P.J. and Venter, J. (2008) A risk evaluation approach for pit slope design, in Proceedings 42nd US Rock Mechanics Symposium and 2nd US-Canada Rock Mechanics Symposium 2008, ARMA 2008, June-July 2008, San Francisco, California USA, Curran Associates Inc., New York, pp. 833-850.

Szendrei, T. (2013) Energy of cavity formation in rocks: Calculation of dynamic expansion of spherical cavities in coal, sandstone, norite and quartzite, Dynamic Physics Consultants for AEL Mining Services, Johannesburg, February 2013, $34 \mathrm{p}$.

Wyllie, D. and Mah, C. (2004) Rock slope engineering civil and mining, based on Hoek, E. and Bray, J. (2001) 3rd edition, Taylor and Francis Group, London, 4th edition, pp. 245-275. 